\title{
Introdução à Teoria de Galois
}

\section{Lucio Centrone, Luan Soares*}

\begin{abstract}
Resumo
A álgebra abstrata é o ramo da matemática que estuda as estruturas algébricas tais como: grupos, anéis, corpos, espaços vetoriais, módulos e álgebras. A teoria de Galois é uma das importantes teorias dessa área da matemática e possui diversas aplicações teóricas e práticas, como por exemplo responder problemas clássicos da geometria referentes a construção com régua e compasso, ou o porquê de não ser possível encontrar uma fórmula para as raízes de uma equação polinomial de grau cinco ou maior usando apenas operações usuais (adição, multiplicação, subtração e divisão) e aplicação de radicais. Neste trabalho, foram desenvolvidas a teoria de grupos, anéis e corpos necessárias para provar o clássico teorema de Abel usando os estudos feitos por Galois.
\end{abstract}

\section{Palavras-chave:}

Álgebra, Teoria de Galois, Teorema de Abel.

\section{Introdução}

Em matemática, uma equação algébrica é uma equação da forma $\mathrm{P}=\mathrm{Q}$, onde $\mathrm{P}$ e $\mathrm{Q}$ são polinômios com coeficientes em um certo corpo. Elas são a base de estudo para várias áreas da matemática moderna como: A teoria algébrica dos números que é o estudo das equações algébricas de uma variável sobre o corpo dos racionais. Na teoria dos corpos, uma extensão algébrica é uma extensão tal que todo elemento é raiz de uma equação algébrica sobre um corpo base. A teoria da transcendência estuda os números reais que não são raízes de nenhuma equação algébrica sobre o corpo dos racionais. As equações diofantinas são equações polinomiais com coeficientes inteiros nas quais se está interessado nas soluções inteiras. A geometria algébrica é o estudo das soluções em um corpo algebricamente fechado de equações polinomiais multivariadas.

\section{Resultados e Discussão}

Enunciamos e provamos os resultados mais fundamentais da teoria de grupos e anéis, noções que são as mais básicas para o início do estudo de álgebra. Em anéis, definimos e construimos o conceito formal de polinômios, objeto principal de estudo. Já em corpos, houve um desevolvimento mais interessante a respeito da construção de corpos usando domínios de integridade e os primeiros usos dos anéis de polinômios sobre um corpo genérico. O estudo mais completo de polinômios, incluido o corpo das funções racionais em $\mathrm{N}$ variáveis, foi fundamental para avançar na teoria de Galois, onde foram formalizados conceitos citados na introdução.

O resultado mais importante deste trabalho e o da teoria de Galois é a relação encontrada pelo francês entre a estrutura dos grupos e corpos, este teorema ficou conhecido como teorema fundamental da teoria de Galois. Mais especificamente, dado um polinômio $f(x)$ e um corpo $K$ onde $f(x)$ possui todas as suas raízes, ao deixar um grupo (chamado grupo de galois) agir sobre as raízes desse polinômio, percebemos uma simetria. Foi exatamente o que Galois fez, ele estudou os grupos de permutação das raízes dos polinômios e isso o levou a uma condição necessária e suficiente para saber quando um polinômio é solúvel por radicais ou não. O grupo de Galois é a chave para isso. Com a definição apresentada para a solubilidade de um grupo, o grupo de Galois de um polinômio $f(x)$ é solúvel se, e somente se, o polinômio é solúvel por radicais. Isso ficou conhecido como a correspondência de Galois.

\section{Conclusão}

Enunciamos todas as ideias importantes para chegar ao último resultado, objetivo de toda a construção, o teorema de Abel. Foram demonstradas algumas teoremas com certas restrições mas mantendo um bom nível de generalidade. A teoria desenvolvida é repleta de aplicações, que podem ser encontradas nas referências bibliográficas ou em qualquer livro básico de álgebra.

\section{Agradecimentos}

Agradeço especialmente ao meu orientador, Lucio Centrone, quem me indicou esse projeto de estudo dessa área tão fascinante da álgebra. Agradeço também ao IMECC por toda a estrutura de apoio aos seus alunos, ao programa PIBIC e ao CNPq pela excelente oportunidade.

\footnotetext{
${ }^{1}$ Herstein, I. N. Topics in Algebra. $2^{\text {nd }}$ ed. New York: John Wiley \& Sons, 1975.

${ }^{2}$ Garcia, A.; Lequain, Y. Elementos de Álgebra. $6^{\text {nd }}$ ed. Rio de Janeiro: IMPA, 2015.

${ }^{3}$ Piacentini, G. M. Algebra un approccio algoritmico. $1^{\text {nd }}$ ed. Italia: Zanichelli, 1996.
} 